\title{
O LETRAMENTO VISUAL COMO EXPERIÊNCIA ESTESIOLÓGICA
}

\author{
A.G. S. BEZERRA* e K. O. PORPINO \\ Universidade Federal do Rio Grande do Norte - UFRN \\ arteilza@hotmail.com*
}

Artigo submetido em novembro/2014 e aceito em junho/2015

DOI: $10.15628 /$ holos.2015.2554

\section{RESUMO}

O presente artigo objetiva discutir o letramento visual como experiência estesiológica, considerando as imagens como artefatos da cultura visual e a mediação da leitura da visualidade como estesia do corpo. Trata-se de um recorte da pesquisa de Doutorado em Educação, a qual estabelece diálogos com a Fenomenologia da Percepção, Alfabetismos Múltiplos e a Formação Docente. Com base na Fenomenologia, a pesquisa entrelaça experiências do mundo vida do pesquisador e de outros docentes das escolas municipais do Natal-RN (Brasil), no cenário da Formação Docente Continuada em Artes - FDCA. Nesse contexto, considera-se a circularidade entre descrição, redução, interpretação, intencionalidade, compreensão e ação. A tese defendida é que o espaço tempo da FDCA irradia um estilo de ser docente mediador da leitura da visualidade como experiência sensível do corpo, sendo a abertura para o mundo um acontecimento do olhar e ler é atribuir sentidos às coisas, às palavras, às imagens, aos sons, ao toque: uma experiência que convida os docentes a agirem quando afetados por ela e se faz estética/estesiológica enlaçando-os por inteiro.

PALAVRAS-CHAVE: Leitura da Visualidade, Estesia, Corpo, Formação Docente, Artes.

\section{THE VISUAL LITERACY AS AN ESTHESIOLOGICAL EXPERIENCE}

\begin{abstract}
This paper aims to discuss the visual literacy as an esthesiological experience considering the images as visual culture artefacts and the mediation of the reading of the visuality as a body aesthesia. This work is a frame of a doctorate research in Education, which establishes bonds among the Phenomenology of Perception, Multiple Literacies and the Teacher's Education. Based on the Phenomenology, the current study crosses the world experiences lived by this researcher and the other teachers of public schools in Natal-RN (Brazil) in a scenario of Teacher's Continuous Education in Arts. In that context, it is considered the circularity among
\end{abstract}

description, reduction, interpretation, intentionality, comprehension and action. The defended thesis proposes that the time for the continuous education in Arts enhances a style of being a mediator of the visuality teacher as a sensitive experience of the body. The required opening for the world consists in a look happening in which reading attribute senses to the things, words, images, sounds and the touch: an experience which invites the teachers to act when affected by that one and it is constituted fully esthetical/esthesiological.

KEYWORDS: Reading of the Visuality, Esthesia, Body, Teacher's Education, Arts. 


\section{INTRODUÇÃO}

O presente artigo objetiva discutir o letramento visual como experiência estesiológica, considerando as imagens como artefatos da cultura visual e a mediação da leitura da visualidade como estesia do corpo. Para o desencadeamento da discussão do letramento visual, organizamos nossos argumentos a partir de três dimensões: a primeira delas, no tópico dois, denomina-se "Leitura da visualidade como estesia do corpo", na qual discutiremos a respeito da visualidade pelos horizontes da fenomenologia e da cultura visual, apresentando a leitura como uma experiência sensível do corpo mediada pelo olhar leitor para além da decodificação de textos verbais. No tópico três, a segunda dimensão intitulada "Da leitura ao letramento visual" situa o leitor a respeito da origem e noções do termo letramento tal qual a concebemos no Brasil e neste estudo. E na terceira e última dimensão, tópico quatro, ressaltamos "A dimensionalidade mediadora emergente no olhar leitor" destacando que no contexto da formação docente continuada irradia-se um estilo de ser mediador tendo em vista o letramento visual como experiência estesiológica.

\section{LEITURA DA VISUALIDADE COMO ESTESIA DO CORPO}

As práticas sociais estão imersas na cultura visual ${ }^{1}$ pelas quais crianças, adolescentes, jovens e adultos convivem cotidianamente com as imagens sejam elas impressas, corporais e virtuais circuladas em diferentes mídias e gêneros discursivos. Desde criança, imersos na visualidade, produzimos e consumimos imagens com as quais convivemos e nos movemos, dimensões do nosso modo de ver, ser e agir no mundo.

Existimos nessa cultura visual, com a qual o corpo dialoga, estabelece relações e da qual informações e mensagens nos tornam visíveis valores, crenças, desejos, fantasias e reflexões para a vida mediando modos de viver que na sua maioria privilegia o consumismo e o individualismo, incentivando cada vez mais atitudes de discriminação, de preconceito, de indiferença e de violência entre as pessoas. Ver, então, "é um pensamento que decifra estritamente os signos dados no corpo" (MERLEAU-PONTY, 2013, p. 31). E este modo de ver, pelo olhar, provoca abertura para o mundo cuja visualidade o corpo abraça.

Essa visualidade presentificada no mundo da cultura como, por exemplo, no corpo, no poema, no espetáculo de dança, numa cena urbana ou rural, no cinema, na textura de uma roupa que vestimos, na capa do caderno de um estudante, no ciberespaço ou em outro objeto artístico/estético precisa ser lida, ou seja, compreendida e interpretada uma vez que o ato de ver entrelaça-se entre o real e o imaginário, o visível e o invisível, a presença e a ausência, uma vivência estética do olhar como experiência sensível do corpo. Há de se aprender a ver/ler essa visualidade para convivermos numa comunidade de vida solidária, colaborativa e humanizante. Conforme Merleau-Ponty (2013)

É preciso tomar ao pé da letra o que nos ensina a visão: por ela tocamos o sol, as estrelas, estamos ao mesmo tempo em toda parte, tão perto dos lugares distantes quanto das coisas próximas, e que mesmo nosso poder de

\footnotetext{
${ }^{1}$ Para Hernández (2010, p. 77), o termo cultura visual compreende: a) um campo de estudo que indaga sobre as práticas de olhar e os efeitos do olhar para quem olha; b) um guarda-chuva sobre qual se incluem imagens, objetos e artefatos do passado e do presente que dão conta como vemos e somos vistos; c) uma condição cultural que, especialmente na época atual, marcada por nossas relações com as Tecnologias de Informação e Comunicação (TIC's), afeta o modo como vemos a nós mesmos e ao mundo.
} 
imaginarmo-nos alhures - 'Estou em Petersburgo em minha cama, em Paris, meus olhos veem o sol' - de visarmos livremente, onde quer que estejam, seres reais, esse poder recorre ainda à visão, reemprega meios que obtemos dela. Somente ela nos ensina que seres diferentes, 'exteriores', alheios um ao outro, existem no entanto absolutamente juntos em 'simultaneidade' [...] (MERLEAUPONTY, 2013, p. 52)

Toda imagem ${ }^{2}$ é prenhe de significados e sentidos, embora sua leitura na totalidade não possa ser alcançada. Não porque somos incapazes de compreendê-la e de interpretá-la e sim pelos diferentes pontos de vista e sentidos que tanto um leitor quanto uma leitora vão atribuindo ao realizar sua leitura. A imagem seja um artefato da cultura visual ou um objeto artístico nos afeta e somos afetados por ela pelo olhar leitor/estético haja vista a dimensão estética ser constitutiva do potencial humano e o olhar leitor uma vivência que se faz estética pela leitura como experiência sensível do corpo. Leitura esta que "[...] para além dos 'dados visuais', dá acesso a uma textura do ser da qual as mensagens sensoriais discretas são apenas as pontuações ou as cesuras, textura que o olho habita como o homem em sua casa" (MERLEAUPONTY, 2013, p. 24). Leitura que nos faz ver o visível e nos conduz a navegar por um olhar desamarrado como nos convida o poema Receita de Olhar ${ }^{3}$, de Roseana Murray:

\author{
Nas primeiras horas da manhã \\ desamarre o olhar, deixe que se derrame \\ sobre todas as coisas belas \\ o mundo é sempre novo \\ e a terra dança e acorda em acordes de sol. \\ Faça do seu olhar imensa caravela.
}

No poema, Roseana Murray pela arte da palavra questiona a mesmice do olhar que olha e não vê. Olhar este já impregnado pelas coisas rotineiras quase sempre fixas e imutáveis vinculado a lógica do pensamento linear. Olhar padronizado e normatizado que dificulta ver o invisível no visível. Entre o título do poema e seus versos, a escritora sugere a abertura para novos horizontes dialogando com o espaço e o tempo do real e do imaginário onde tudo muda, tudo passa e a experiência vivida é irrepetível. No dizer de Georges Didi-Huberman (2010, p. 33), "[...] cada coisa a ver, por mais exposta, por mais neutra de aparência que seja, torna-se inelutável quando uma perda a suporta - ainda que pelo viés de uma simples associação de ideias, mas constrangedora, ou de um jogo de linguagem -, e desse ponto nos olha, nos concerne, nos persegue". Trata-se de "dá existência visível ao que a visão profana crê invisível, faz que não tenhamos necessidade de 'sentido muscular' para ter a voluminosidade do mundo" (Merleau-Ponty, 2013, pp. 23-24). A poeta convida o olhar leitor a abrir-se para a eterna novidade do mundo pressupondo uma leitura da visualidade como estesia do corpo.

\title{
3 DA LEITURA AO LETRAMENTO VISUAL
}

O sentido de leitura da visualidade como estesia do corpo extrapola o entendimento do

\footnotetext{
${ }^{2}$ Para José Ortega y Gasset (2011), enquanto a imagem é uma forma de exposição gestáltica do pensamento, a visualidade é a forma sígnica dessa imagem. O simbólico, o metafórico e a forma coexistem no movimento de visibilidade e invisibilidade.

${ }^{3}$ Poema compartilhado como Leitura Poiésis na abertura do primeiro encontro da Formação Docente Continuada em Artes/Estação Ensino de Artes Visuais, em 16 de abril de 2012, com professores das escolas municipais do Natal-RN (Brasil).
} 
ato de ler para além da decodificação de textos verbais escritos. A leitura compreendida nessa dimensão, ancorada à perspectiva sociocultural e à abordagem fenomenológica, se aproxima das ideias de Paulo Freire ao dizer que a "leitura de mundo precede à leitura da palavra" e o ato de ler imagens como uma atitude fenomenológica amplia a formação humana seduzindo-a para agir no mundo visualmente complexo com afetividade, sensibilidade, solidariedade e criticidade. Para Barbosa (2009)

Temos que alfabetizar para a leitura de imagem. Através das leituras das obras de artes [...] estaremos preparando o público para a decodificação da gramática visual, da imagem fixa e, através da leitura do cinema, da televisão e dos CDROM o preparamos para aprender a gramática da imagem em movimento. Essa decodificação precisa ser associada ao julgamento da qualidade do que está sendo visto aqui e agora e em relação ao passado. Preparando-se para o entendimento das artes visuais se prepara para o entendimento da imagem quer seja arte ou não" (BARBOSA, 2009, p. 36)

Ana Mae Barbosa (2009) ao discutir sobre a alfabetização visual e a imagem no ensino da arte constrói um sistema epistemológico representado pela triangulação leitura, contextualização e criação, difundida erroneamente pelos educadores por metodologia triangular e reconhecida recentemente por essa pesquisadora como abordagem triangular na obra intitulada "Abordagem Triangular no ensino das Artes e Culturas Visuais" (2010).

Apesar dessa abordagem ter sua gênese no universo da arte visual, ela é plural e transdisciplinar. A título de ilustração podemos citar dois artigos e seus respectivos autores que desenvolvem suas pesquisas por esse enfoque, são eles: “De tripé em tripé: o caleidoscópio do ensino da dança", de Isabel Marques (Caleidos/SP) e "Formação Continuada de professores e a abordagem triangular de Ensino da Arte", de Everson Silva e Clarissa de Araújo" (UFPE);

Hernández (2007) por sua vez, baseado na concepção de Multiletramentos, propõe os "alfabetismos múltiplos e alfabetismo visual crítico" como uma possibilidade mediadora nos estudos da cultura visual e no ensino de Artes. Para este pesquisador, torna-se relevante estes estudos como referência para a formação em Artes para que aconteça a revisão dos sentidos de seus fundamentos, de suas finalidades, do seu currículo e das práticas pedagógicas.

Ao empregar o termo "alfabetismo", Hernández busca distingui-lo das noções de "alfabetização" e de "analfabetismo" conforme é concebida pela pedagogia tradicional: uma tentativa de aproximação do termo à ideia da noção literacy em inglês e letramento no Brasil. “[...] o importante não é apenas aprender a ler os textos, mas também - como escreveu Paulo Freire - interpretar o mundo para atuar nele a partir de uma conscientização que leve à emancipação", comenta Hernández (2007, p. 58). Ao propor os alfabetismos múltiplos, este pesquisador, introduz uma narrativa educacional em Artes próxima à concepção dos Multiletramentos, abrindo espaço para estudarmos o letramento visual.

Introduzido no Brasil, na década de 1980, a palavra letramento sob influência do inglês "literacy" era traduzido, até então, por alfabetização entendida como apropriação de códigos linguísticos referentes aos modos de ler e escrever das pessoas, cujo termo alfabetizado nos remete de imediato à imagem daquele que aprendeu, ao decodificar os códigos, as primeiras letras. Conforme Morttati (2004) o uso pela primeira vez do termo letramento aparece na apresentação do livro de Mary Kato, intitulado "No mundo da escrita: uma perspectiva 
sociolinguística", de 1986. Posteriormente, nos anos de 1988, 1995, 1998 o termo vai sendo amplamente discutido e divulgado a partir respectivamente das pesquisas realizadas pelas brasileiras Leda Tfouni, Ângela Kleiman e Magda Soares.

No apagar das luzes da década de 1990, com as novas demandas sociais e culturais no campo comunicacional e das novas tecnologias, ler não corresponde somente a decodificação dos códigos, mas implica estabelecer relações situando-se no contexto, hipertextos e hipermídias, o que requer compreensão e produção de sentidos para além da decodificação do texto verbal.

Este entendimento, nos apresenta assim a limitação conceitual do termo alfabetização para as demandas sociais da atualidade, extrapolando o campo originalmente da linguística para o campo das diferentes linguagens e da dimensão sociocultural. Para Mortatti (2004), no âmbito da dimensão social e cultural, letramento refere-se ao conjunto de práticas sociais nas quais os eventos e as práticas de letramento são plurais, suscitando dos sujeitos diferentes habilidades e conhecimentos de leitura e de escrita em quaisquer que sejam os textos produzidos.

Considerando que os eventos e as práticas de letramento são plurais e entendendo que alfabetização tal qual compreende a pedagogia tradicional da linguagem materna não dá conta da formação humana para conviver na diversidade cultural e com a multiplicidade dos discursos presentes nas múltiplas linguagens do mundo atual, Kalanzis e Cope (1996) pesquisadores australianos, juntamente com os demais integrantes do THE NEW LONDON GROUP (1996), cunharam o termo multiletramentos. Grupo este constituído por 10 (dez) pesquisadores/educadores de distintas áreas do conhecimento, provenientes dos Estados Unidos, da Austrália e da Grã-Bretanha que começaram a se reunir no ano de 1994 - em New London/New Hampshire, nos Estados Unidos - para discutir o estado atual da pedagogia da alfabetização. Para estes pesquisadores, a noção de multiletramentos supera a pedagogia da alfabetização tradicional, abordando aspectos da multiplicidade textual tais como: textos escritos, visuais, sonoros, dentre outros textos, haja vista a crescente proeminência da diversidade cultural e da linguagem por meio dos múltiplos canais de comunicação, de circulação da informação e midiático. Atualmente no Brasil, na área da linguística, a pesquisadora Roxane Rojo (2009) aproxima-se dessa discussão em seu livro “Letramentos Múltiplos, Escola e Inclusão Social", sendo uma referência em multiletramentos na área a qual é pesquisadora.

Com base nestes novos estudos cuja referência são os multiletramentos, termo este cunhado pelo The New London Group (1996) e os alfabetismos múltiplos de Hernández (2007) cada vez mais ampliam-se o emprego e as concepções do termo letramento em distintas áreas do conhecimento: "letramento em matemática", "letramento em computação", "letramento em ciências", dentre outros. Nos interessa, entretanto neste estudo, o Letramento Visual como experiência estesiológica. Este letramento diz respeito às práticas sociais nas quais os eventos e as práticas de letramento emergem da cultura visual, suscitando do sujeito uma atitude para ver e para ler a visualidade por meio da experiência estética do olhar leitor.

Ler a visualidade com sensibilidade, competência e criticidade, percebendo aspectos e nuances imbricadas na visibilidade e na invisibilidade faz parte do processo de apreensão, leitura para compreensão do mundo e de nossa própria existência. Um olhar leitor que se faz pintor do visível porque ver "[...] é o meio que me é dado de estar ausente de mim mesmo, de assistir por dentro à fissão do ser, ao término da qual somente me fecho sobre mim" (MERLEAU-PONTY, 
2013, p. 51). E a leitura da visualidade uma atitude da percepção sinestésica do sujeito pois entre os sentidos há uma comunicabilidade cuja abertura produz o diálogo entre corpo, cultura, mundo. Sobre essa percepção sinestésica é muito apropriada a descrição merleau-pontyana a seguir: "No movimento do galho que um pássaro acaba de abandonar, lemos sua flexibilidade ou sua elasticidade [...] Vemos o peso de um bloco de ferro que se afunda na areia, a fluidez da água, a viscosidade do xarope" (MERLEAU-PONTY, 2006, p. 309).

Ler é atribuir sentidos às coisas, às palavras, às imagens, aos sons, ao toque, à gestualidade enfim um ato que envolve o sujeito por inteiro. Trata-se de ler os artefatos e as manifestações das culturas visuais, incluindo-se os objetos artísticos/estéticos, objetos estes promotores de inclusão ou exclusão, entendendo-as como mediadores dos discursos e das posições dos sujeitos. É preciso aprender a pensar em termos de significados, de práticas sociais e de relações de poder concernentes às experiências de olhar e ser olhado. Explorando o papel que a imagem tem na construção de olhares e de sentidos sobre quem olha e sobre a realidade que se olha.

As experiências de olhar e ser olhado e os sentidos de quem se olha e sobre a realidade que se olha, nos remete a um modo de ver cujo diálogo entre visível e invisível pressupõe um olhar habitado no corpo. Este pressuposto desvela a relação de pertencimento entre o visível, o tangível e a experiência sensível. O corpo que olha é o mesmo corpo que é tocado. Logo, o Letramento Visual, enquanto fenômeno complexo, tal qual o sentido que estamos apreendendo, também é uma experiência no/do corpo na perspectiva fenomenológica. Conforme MerleauPonty (2009),

É preciso que nos habituemos a pensar que todo visível é moldado no sensível, que todo ser táctil está voltado de alguma maneira à visibilidade, havendo, assim, imbricação e cruzamento, não apenas entre o que é tocado e o que toca, mas também entre o visível e o tangível que nele está incrustado, do mesmo modo que, inversamente, este não é uma visibilidade nula, não é sem uma existência visual (MERLEAU-PONTY, 2009, p. 131)

Merleau-Ponty (2009), nos provoca e nos mobiliza para a compreensão dos sentidos evidenciados na reversibilidade de um corpo que é da experiência e da linguagem. Nessa perspectiva, delimitamos o estudo em foco de "O Letramento Visual como experiência Estesiológica". Um diálogo construído entre 'Alfabetismos Múltiplos da cultura visual' (HERNÁNDEZ, 2007), a 'Fenomenologia da Percepção'”, de Merleau-Ponty (2006) e a Formação Docente.

\section{A DIMENSIONALIDADE MEDIADORA/FORMATIVA DO OLHAR LEITOR}

$\mathrm{Na}$ atualidade, numa sociedade entranhada pela cultura visual produzida tanto por artefatos tradicionais quanto por artefatos das novas tecnologias, geradores de múltiplos textos imagéticos, urge que nos apropriemos de um modo de ver/ler para além das aparências e das superficialidades propostas, principalmente, pelas imagens da publicidade. Sendo assim, formar leitores da visualidade e mediadores desta leitura letrando-os para a vida parece-nos uma emergência educacional e planetária.

Na educação escolarizada, a mediação do professor ou da professora é primordial para a 
formação de leitores da visualidade. Diante desta assertiva, defendemos que o espaço tempo da Formação Docente Continuada irradia um estilo de ser docente mediador da leitura da visualidade como experiência sensível do corpo, sendo a abertura para o mundo um acontecimento do olhar e ler é atribuir sentidos às coisas, às palavras, às imagens, aos sons, ao toque: uma experiência que convida os docentes a agirem quando afetados por ela e se faz estética/estesiológica enlaçando-os por inteiro.

Por meio da experiência estética do olhar leitor, no cenário da Formação Docente Continuada realizada com professores e professoras da área de $\operatorname{Artes}^{4}$ das Escolas do Ensino Fundamental, na cidade do Natal, estado do Rio Grande do Norte - Brasil, o (a) docente é convidado (a) a agir como mediador (a) de letramento visual, cujas práticas de letramento configuram uma dimensionalidade ${ }^{5}$ mediadora de ser docente em que o olhar leitor habita 0 corpo do sujeito da formação.

A título de ilustração, narramos sucintamente a seguir uma vivência com uma dessas práticas. Nesta vivência, realizada em 16 de abril de 2012, as professoras e os professores foram afetados pelo olhar da autoimagem no espelho, sendo convidados a criarem o autorretrato pela linguagem do desenho com o uso de grafite, papel sulfite e giz de cera.

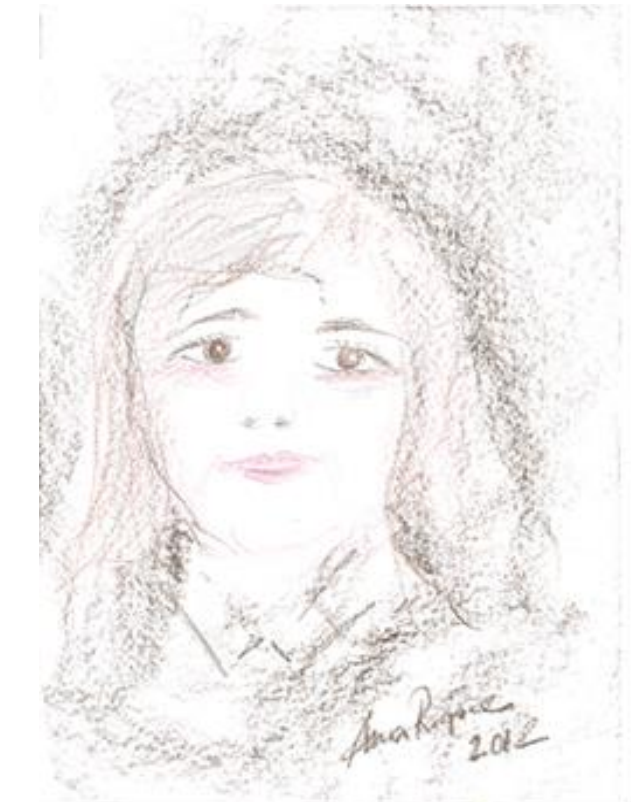

Figura 1: Autorretrato da professora da área de Artes Visuais

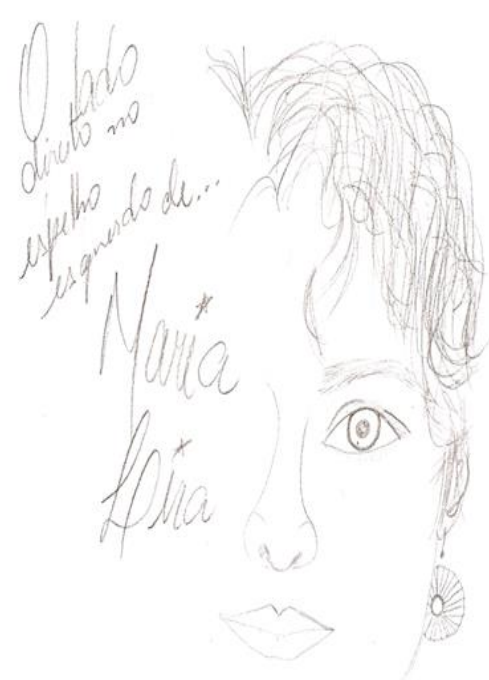

Figura 2: Autorretrato da professora da área de Artes Cênicas

O autorretrato da Figura 1, de autoria de uma docente da área de Artes Visuais embora tenha empregado o preto como uma cor dominante, a tonalidade roseada impregna leveza ao desenho dando visibilidade a uma jovialidade de um tempo de vida da docente que não é o

\footnotetext{
${ }^{4}$ De acordo com a Resolução no 1, de 31 de janeiro de 2006, o Conselho Nacional de Educação/Câmara de Educação Básica denomina Artes o componente curricular referente ao ensino e a aprendizagem das linguagens artísticas - artes visuais, dança, música e teatro - nas escolas brasileiras de Educação Básica. Na Rede Municipal de Educação do Natal/RN, a Formação Docente Continuada em Artes acontecendo desde o ano 2000, realiza-se atualmente quinzenalmente, nos turnos matutino e vespertino, com uma média de (80) docentes cursistas participando em cada encontro presencial.

${ }^{5} \mathrm{Na}$ visão merleau-pontyana (2009), a dimensionalidade é uma "propriedade primordial que a carne tem de estando aqui e agora, irradiar por toda parte e para sempre, de sendo indivíduo, também ser dimensão e universal".
} 
cronológico. $\mathrm{O}$ outro, da Figura 2, de autoria de uma docente da área das artes cênicas torna visível o inelutável paradoxo do ato de ver. Ambas desvelam um estilo de ser docente mediador, uma dimensionalidade proveniente da formação do olhar leitor baseada na leitura da visualidade como estesia do corpo.

Georges Didi-Huberman, na obra "O que vemos, o que nos olha", argumenta "O que vemos só vale - só vive - em nossos olhos pelo que nos olha. Inelutável porém é a cisão que separa dentro de nós o que vemos daquilo que nos olha. [...] o ato de ver só se manifesta ao abrir-se em dois" (2010, p. 29). Entre o que eu vejo e o que me olha, ausência e presença imbricam-se na visualidade.

Há um modo de ver, há um modo de ler, há um modo de ser docente mediador de leitura da visualidade. Trata-se de acontecimentos de corpos implicados na dimensionalidade mediadora/formativa na qual a leitura é uma dimensão movida por uma atitude da percepção sinestésica do sujeito. As Figuras 1 e 2 que nos olha, por exemplo, tecem uma narrativa dessa percepção vivenciada nesse contexto da Formação Docente.

Portanto, a noção de dimensionalidade merleau-pontyana nos fala de uma particularidade e diferenciação que desvela um estilo de ser docente mediador. Uma propriedade dimensional que pela percepção sinestésica enlaça o corpo por inteiro do docente durante as práticas de letramento visual experienciadas na Formação Docente Continuada em Artes, vivências nas quais por meio da experiência estética do olhar leitor convidam o professor e a professora para aprender a ver, a criar e a ler a visualidade como experiência estesiológica.

\section{REFERÊNCIAS BIBLIOGRÁFICAS}

1. BARBOSA, Ana Mae. A imagem no ensino da arte: anos 1980 e novos tempos. São Paulo: Perspectiva, 2009.

2. Ana Mae. (Org.) Abordagem Triangular: no ensino das artes e culturas visuais. São Paulo: Cortez Editora, 2010.

3. DIDI-HUBERMAN, Georges. O que vemos, o que nos olha. Tradução: Paulo Neves. São Paulo: Editora 34, 2010.

4. HERNANDEZ, Fernando. Catadores da Cultura Visual. Porto Alegre: Editora Mediação, 2007.

5. MERLEAU-PONTY, Maurice. Fenomenologia da Percepção. 3a ed. Tradução. Carlos Alberto Ribeiro de Moura. São Paulo: Martins Fontes, 2006.

6. Maurice. 0 visível e o invisível. 4ạ edição. Tradução: José Artur Gianotti e Armando Mora d'Oliveira. São Paulo: Perspectiva, 2009.

7. — Maurice. O Olho e o Espírito. 1a edição. Tradução: Paulo Neves e Maria Ermantina Galvão Gomes Pereira. São Paulo: Cosacnaify Portátil, 2013.

8. MORTATTI, M. R. L. Educação e Letramento. São Paulo: UNESP, 2004.

9. ORTEGA Y GASSET, José. Ensaios de Estética. Tradução: Ricardo Araújo. São Paulo: Cortez, 2011.

10. THE NEW LONDON GROUP. The Pedagogy of Multiliteracies: Designing Social Futures. 1996. Disponível em: http://wwwstatic.kern.org/filer/blogWrite44ManilaWebsite/paul/articles/A_ Pedagogy_of_Multiliteracies_Designing_Social_Futures.htm Acesso em 02/06/2014 